\title{
Multivalent histone engagement by the linked tandem Tudor and PHD domains of UHRF1 is required for the epigenetic inheritance of DNA methylation
}

\author{
Scott B. Rothbart, ${ }^{1,2}$ Bradley M. Dickson, ${ }^{3,8}$ Michelle S. Ong, ${ }^{4,5,6,7,8}$ Krzysztof Krajewski, $^{1,8}$ \\ Scott Houliston, ${ }^{4,5,6,7}$ Dmitri B. Kireev, ${ }^{3}$ Cheryl H. Arrowsmith, ${ }^{4,5,6,7}$ and Brian D. Strahl ${ }^{1,2,9}$ \\ ${ }^{1}$ Department of Biochemistry and Biophysics, University of North Carolina at Chapel Hill, Chapel Hill, North Carolina 27599, \\ USA; ${ }^{2}$ Lineberger Comprehensive Cancer Center, University of North Carolina at Chapel Hill, Chapel Hill, North Carolina \\ 27599, USA; ${ }^{3}$ Center for Integrative Chemical Biology and Drug Discovery, Division of Chemical Biology and Medicinal \\ Chemistry, University of North Carolina Eshelman School of Pharmacy, University of North Carolina at Chapel Hill, Chapel \\ Hill, North Carolina 27599, USA; ${ }^{4}$ Structural Genomics Consortium, University of Toronto, Toronto, Ontario M5G 1L7, \\ Canada; ${ }^{5}$ Department of Medical Biophysics, University of Toronto, Toronto, Ontario M5S 1A8, Canada; ${ }^{6}$ Ontario Cancer \\ Institute, Toronto, Ontario M5G 2M9, Canada; ${ }^{7}$ Campbell Family Cancer Research Institute, Toronto, Ontario M5G 2M9, \\ Canada
}

Histone post-translational modifications regulate chromatin structure and function largely through interactions with effector proteins that often contain multiple histone-binding domains. While significant progress has been made characterizing individual effector domains, the role of paired domains and how they function in a combinatorial fashion within chromatin are poorly defined. Here we show that the linked tandem Tudor and plant homeodomain (PHD) of UHRF1 (ubiquitin-like PHD and RING finger domain-containing protein 1) operates as a functional unit in cells, providing a defined combinatorial readout of a heterochromatin signature within a single histone $\mathrm{H} 3$ tail that is essential for UHRF1-directed epigenetic inheritance of DNA methylation. These findings provide critical support for the "histone code" hypothesis, demonstrating that multivalent histone engagement plays a key role in driving a fundamental downstream biological event in chromatin.

[Keywords: histone code; UHRF1; DNMT1; multivalency; epigenetic inheritance; DNA methylation]

Supplemental material is available for this article.

Received April 23, 2013; revised version accepted May 10, 2013.

Histone post-translational modifications (PTMs) and DNA methylation are two key epigenetic regulators of DNA information in chromatin. The N-terminal and C-terminal tails of histones are rich in PTMs, including methylation, acetylation, phosphorylation, and ubiquitination (Kouzarides 2007; Tan et al. 2011). Histone PTMs have been shown to alter the physical structure of chromatin (Shogren-Knaak et al. 2006) and may function in the form of a "histone code" to facilitate the binding of effector proteins that elicit selective effects on chromatin-templated biological processes like gene expression and DNA repair (Strahl and Allis 2000; Jenuwein and Allis 2001; Taverna et al. 2007).

Effector proteins associate with (i.e., "read") specific PTMs and surrounding residues on histone tails through

\footnotetext{
${ }^{8}$ These authors contributed equally to this work.

${ }^{9}$ Corresponding author

E-mail brian_strahl@med.unc.edu

Article is online at http://www.genesdev.org/cgi/doi/10.1101/gad.220467.113.
}

specialized recognition domains (Taverna et al. 2007; Musselman et al. 2012a). To date, a wide number of reader domains have been characterized and include modules that bind acetyllysine (e.g., bromodomains), methyllysine (e.g., chromo, Tudor, plant homeodomain [PHD], PWWP, and MBT domains), methylarginine (e.g., Tudor domains), phosphoserine (e.g., 14-3-3 and BRCT domains), and even unmodified histone residues (e.g., ADD and PHD domains) (Taverna et al. 2007; Musselman et al. 2012a). Although many chromatin-associated proteins encode only a single reader module, a significant number of these proteins in fact contain multiple chromatin recognition domains or are partnered with other effector proteins containing one or more reader modules through membership in macromolecular complexes. Thus, multivalent chromatin engagement is likely to be an important aspect of how chromatin-associated proteins function-a concept suggested by the "histone code" hypothesis (Strahl and Allis 2000; Jenuwein and Allis 2001; Ruthenburg et al. 2007). Indeed, several examples of 
multivalent histone engagement by effector proteins have recently been described (Tsai et al. 2010; Eustermann et al. 2011; Ruthenburg et al. 2011; Xi et al. 2011; Ali et al. 2012; Musselman et al. 2012b; Oliver et al. 2012; Qiu et al. 2012). However, the contribution of these combinatorial interactions to the biological functions associated with these proteins remains poorly defined.

The E3 ubiquitin ligase UHRF1 (ubiquitin-like PHD and RING finger domain-containing protein 1 ) is a unique chromatin effector protein in that it integrates the recognition of both histone PTMs and DNA methylation (Arita et al. 2008; Avvakumov et al. 2008; Hashimoto et al. 2008; Nady et al. 2011; Rajakumara et al. 2011). As such, UHRF1 harbors multiple domains that bind chromatin (Fig. 1A). The UHRF1 SET and RING-associated (SRA) domain is a DNA-binding domain that recognizes 5-methylcytosine ( $5 \mathrm{mC})$ and 5-hydroxymethylcytosine in the context of hemimethylated double-stranded $\mathrm{CpG}$ dinucleotides (Arita et al. 2008; Avvakumov et al. 2008; Hashimoto et al. 2008; Qian et al. 2008; Frauer et al. 2011; Spruijt et al. 2013). DNA methylation patterns are established during early embryogenesis by de novo DNA methyltransferases DNMT3a and DNMT3b (with the associated, but noncatalytic, DNMT3L) (Okano et al. 1999; Bourc'his et al. 2001; Jia et al. 2007) and are primarily maintained through somatic cell divisions by the maintenance DNA methyltransferase DNMT1 (Chen et al. 2007). Genetic studies have demonstrated that UHRF1 is essential for faithful DNMT1-mediated maintenance methylation (Bostick et al. 2007; Sharif et al. 2007), and our laboratory determined that the DNA methylation maintenance function of UHRF1 is linked to its ability to engage di- and trimethylated H3K9 (H3K9me2/3) - transcriptionally repressive chromatin marks enriched at pericentric heterochromatin and telomeres (Ebert et al. 2006; Grewal and Elgin 2007; Hawkins et al. 2010; Ernst et al. 2011) - through the first Tudor subdomain of its tandem Tudor domain (TTD) (Fig. 1A,B; Nady et al. 2011; Rothbart et al. 2012a). The adjacent PHD of UHRF1 (Fig. 1A), previously implicated in the regulation of transcription (Rajakumara et al. 2011) and heterochromatin organization (Papait et al. 2007), binds the unmodified $\mathrm{N}$ terminus of histone H3 (Fig. 1B; Hu et al. 2011; Rajakumara et al. 2011; Wang et al. 2011). Crystal structures of the linked TTD-PHD bound to H3K9me3 peptides show that UHRF1 can simultaneously engage the unmodified H3 N terminus and $\mathrm{H} 3 \mathrm{~K} 9 \mathrm{me} 3$ on a single $\mathrm{H} 3$ tail (cis recognition) through this linked recognition module (Fig. 1C; Arita et al. 2012; Cheng et al. 2013), although the UHRF1 TTD and PHD are able to bind histone peptides indepen-

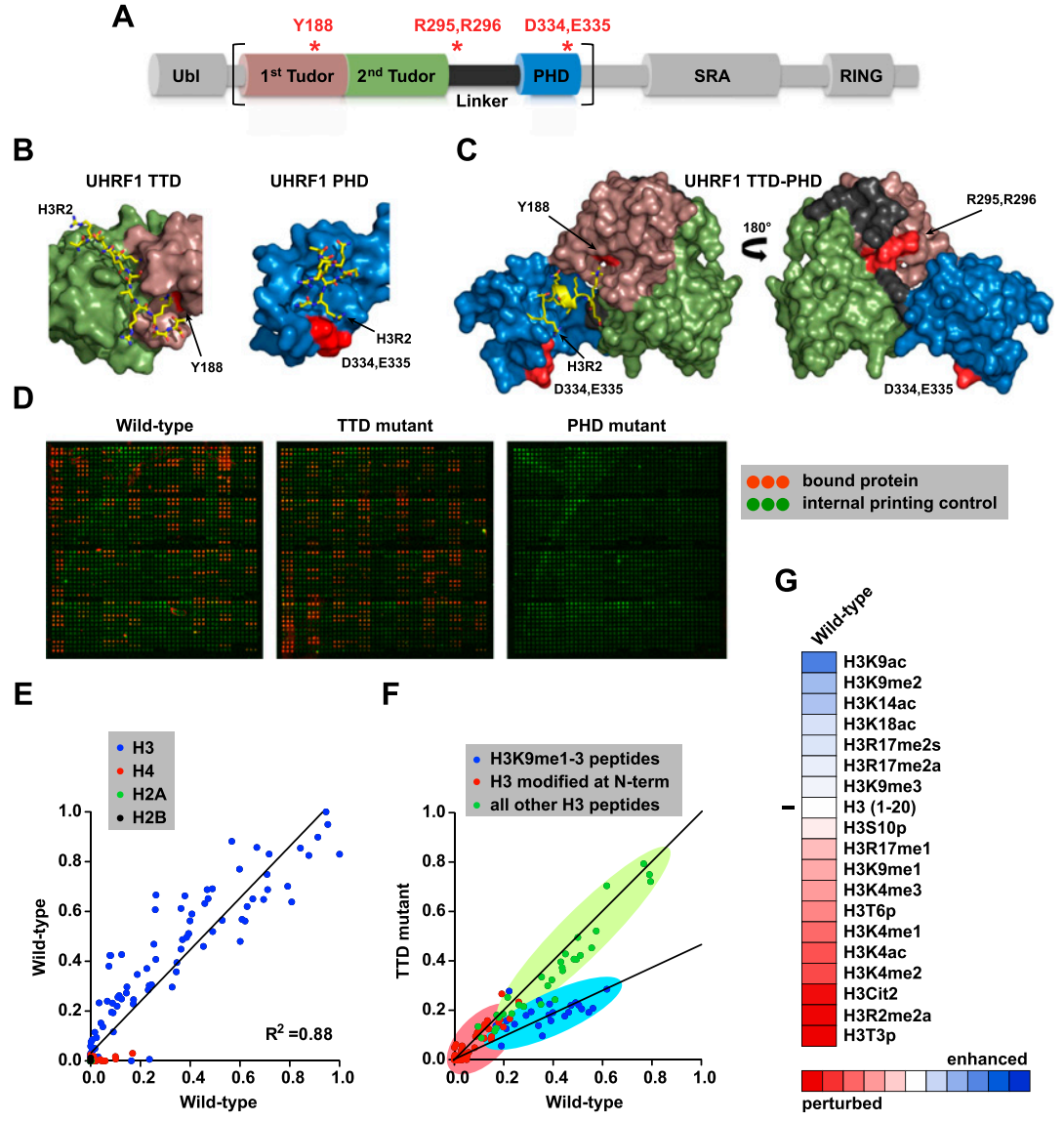

Figure 1. PHD function is critical for UHRF1 TTD-PHD binding in vitro. (A) Domain map of full-length UHRF1. Positions of alanine mutations used in this study are indicated with asterisks. Brackets demarcate the histone-binding module (amino acids 123-366). (B) Surface representations of the UHRF1 TTD (left; PDB: 2L3R) (Nady et al. 2011) and UHRF1 PHD (right; PDB: 3SOU) (Rajakumara et al. 2011) bound to $\mathrm{H} 3_{1-11} \mathrm{~K} 9 \mathrm{me} 3$ and $\mathrm{H} 3_{1-8}$ peptides, respectively. This H3K9me3-TTD interaction is referred to throughout the manuscript as the alternative H3-binding pose with respect to the TTD. (C) Surface representation of the UHRF1 TTD-PHD (PDB: 3ASK) bound to $\mathrm{H} 3_{1-11} \mathrm{~K} 9 \mathrm{me} 3$ peptides. (D) Representative subarrays of peptide microarray scans for the UHRF1 TTDPHD. Peptides (green) are spotted in triplicate four times per subarray (two subarrays per slide) and protein binding (red) was detected as described in the Materials and Methods. (TTD mutant) UHRF1 TTD-PHD Y188A; (PHD mutant) UHRF1 TTD-PHD D334A/E335A. (E) Scatter plot of normalized mean intensities from two peptide microarrays probed with wild-type UHRF1 TTD-PHD. Each spot represents an individual peptide (see Supplemental Table S1 for a full peptide list) and is color-coded by histone as described in the key. $(F)$ Scatter plot of normalized mean intensities (five arrays for wild-type [WT] and three arrays for TTD mutant) for $\mathrm{H} 3$ peptides on the array. Each spot represents an individual peptide and is colorcoded as described in the key. $(G)$ Heat map depicting the effects of single PTMs on the binding of wild-type UHRF1 TTD-PHD to $\mathrm{H}_{1-20}$ peptides. Normalized mean intensities are represented relative to unmodified $\mathrm{H}_{1-20}(0$, white). Enhanced (1, blue) and perturbed $(-1$, red) interactions are depicted. 
dently of one another in vitro (Fig. 1B; Hu et al. 2011; Nady et al. 2011; Rajakumara et al. 2011; Wang et al. 2011). However, it remains to be determined whether multivalent engagement of $\mathrm{H} 3$ by the linked reader modules of UHRF1 is biologically significant.

Here, we comprehensively characterize the specificity, selectivity, and molecular dynamics of the TTD-PHD dual-effector module of UHRF1. Notably, we demonstrate that this structural unit functions as a single histone recognition module in cells, providing a combinatorial readout of a histone $\mathrm{H} 3$ tail in cis that is required for the epigenetic inheritance of DNA methylation. Our findings are among the first to demonstrate that multivalent histone engagement in a defined manner plays a fundamental role in driving a downstream biological event in chromatin, providing critical support for the combinatorial nature of the "histone code" hypothesis.

\section{Results}

The UHRF1 PHD dominates multivalent histone H3 engagement in vitro

To decipher the contribution of the "histone code" on effector protein recognition, we recently developed a high-density (>4000 features) peptide microarray platform harboring a comprehensive library of known single and combinational PTMs on each of the core histone proteins (H3, H4, H2A, and H2B) (Supplemental Table S1; Fuchs et al. 2011; Rothbart et al. 2012b). This technology was recently used to define the isolated UHRF1 TTD as a bona fide $\mathrm{H} 3 \mathrm{~K} 9$ di- and trimethyl reader module (Fig. 1B) and also uncovered a novel and biologically relevant property of the UHRF1 TTD as an H3K9 effector domain that is insensitive to neighboring H3S10 phosphorylation (H3S10p) (Rothbart et al. 2012a). In addition to the TTD, UHRF1 contains an adjacent PHD finger that interacts with the unmodified $\mathrm{N}$ terminus of $\mathrm{H} 3$ (Fig. 1B; Hu et al. 2011; Rajakumara et al. 2011; Wang et al. 2011). Recent structural studies indicated that the linked TTD and PHD domains of UHRF1 simultaneously bind H3K9me3 peptides on a single histone tail in vitro (Fig. 1C; Arita et al. 2012; Cheng et al. 2013). We therefore sought to characterize this multivalent cis interaction further in the context of the "histone code" and asked whether such binding is biologically important for UHRF1 function in the cell.

Peptide microarrays probed with the wild-type UHRF1 TTD-PHD revealed a strong preference for histone $\mathrm{H} 3$ peptides encompassing the N-terminal tail (Fig. 1D,E; Supplemental Fig. S1A). Notably, an aromatic cage mutation of the UHRF1 TTD (Y188A; TTD mutant), previously shown to abolish the interaction with H3K9 methylation (Nady et al. 2011), showed interactions similar to those found with the wild-type dual domain, with the exception that a number of H3K9 methylated peptides that were "strong" hits in the wild-type case (Supplemental Fig. S1B) were shifted slightly to a lower range of detection (Fig. 1D,E). In striking contrast, alanine mutations at two acidic residues in the UHRF1 PHD (D334A/E335A; PHD mutant) (Rajakumara et al. 2011), previously shown to strongly inhibit the isolated PHD interaction with $\mathrm{N}$-terminal $\mathrm{H} 3$ tail peptides (Rajakumara et al. 2011), completely disrupted array binding, even in the presence of a functional TTD (Fig. 1D). Consistent with an important role for the $\mathrm{N}$ terminus of $\mathrm{H} 3$ in TTD-PHD binding, PTMs at the extreme $\mathrm{N}$ terminus of $\mathrm{H} 3$, including asymmetric Arg 2 methylation or citrullination (H3R2me2a and Cit2, respectively), Thr 3 phosphorylation (H3T3p), and Lys 4 acetylation (H3K4ac), strongly perturbed binding of the wild-type UHRF1 TTD-PHD (Fig. 1F,G). Interestingly, while array analysis showed a slight inhibitory effect in the presence $\mathrm{H} 3 \mathrm{~K} 4 \mathrm{me} 3$, in-solution peptide pull-down and isothermal titration calorimetry (ITC) analysis indicated that this change was not significant (data not shown). Collectively, these data suggest that the UHRF1 PHD provides a dominant affinity for the unmodified $\mathrm{N}$ terminus of $\mathrm{H} 3$, while the TTD facilitates the localization of UHRF1 to H3K9me2/3-marked chromatin.

Quantitative analysis of UHRF1 TTD-PHD binding to $H 3 \mathrm{~K} 9 \mathrm{me} 3$ reveals individual domain contributions to multivalency

While peptide microarray analysis is a powerful tool for discriminating between strong and weak binding events, the technology is limited to semiquantitative measures. To further define the contributions of the UHRF1 TTD and PHD to multivalent engagement, we sought to quantify binding events using fluorescence polarization. The UHRF1 TTD-PHD bound tightly to $\mathrm{H} 3_{1-20} \mathrm{~K} 9 \mathrm{me} 2$ $\left(\mathrm{K}_{\mathrm{d}} \sim 0.17 \mu \mathrm{M}\right)$ and $\mathrm{H} 3_{1-20} \mathrm{~K} 9 \mathrm{me} 3\left(\mathrm{~K}_{\mathrm{d}} \sim 0.35 \mu \mathrm{M}\right)$ peptides fluorescently labeled at the $\mathrm{C}$ terminus (Fig. 2A; Supplemental Fig. S1C), consistent with $\mathrm{K}_{\mathrm{d}}$ measurements for H3K9me3 peptides by ITC (Arita et al. 2012). Perturbing the TTD interaction with H3K9 methylation (Y188A; TTD mutant) diminished the affinity for these peptides 10 -fold to 15 -fold ( $\mathrm{K}_{\mathrm{d}} \sim 2.5$ and $4.5 \mu \mathrm{M}$, respectively) (Fig. 2A; Supplemental Fig. S1C). Consistent with microarray results, perturbing the PHD interaction with the $\mathrm{N}$ terminus of H3 (D334A/E335A; PHD mutant) resulted in undetectable binding to $\mathrm{H}_{1-20} \mathrm{~K} 9 \mathrm{me} 2$ and $\mathrm{H} 3_{1-20} \mathrm{~K} 9 \mathrm{me} 3$ peptides fluorescently labeled at the $\mathrm{C}$ terminus (Fig. 2A; Supplemental Fig. S1C).

Many effector modules that recognize the extreme $\mathrm{N}$ terminus of $\mathrm{H} 3$ (residues 1-4)-including the UHRF1 PHD-specifically interact with the $\mathrm{N}$-terminal amino group of Ala 1. Therefore, we predicted that placement of a fluorescent probe on the $\mathrm{N}$ terminus of $\mathrm{H} 3{ }_{1-20} \mathrm{~K} 9 \mathrm{me} 3$ peptides would block PHD interaction with the free $\mathrm{N}$ terminus. Indeed, $\mathrm{N}$-terminal probe placement resulted in no detectable binding to wild-type UHRF1 TTD-PHD or to the individual domain mutants of this dual binding module (Fig. 2A). These results agree with those of Arita et al. (2012), in which no measurable binding of wild-type UHRF1 TTD-PHD was detected by ITC to H3K9me3 peptides acetylated at their N-terminal amino group. Furthermore, binding of the UHRF1 TTD-PHD to $\mathrm{H} 3_{1-20} \mathrm{~K} 9 \mathrm{me} 3$ peptides fluorescently labeled at the $\mathrm{C}$ terminus was outcompeted by unlabeled $\mathrm{H} 3_{1-5}$ peptides containing either L-alanine or L-valine at position 1 but not with unlabeled 
A
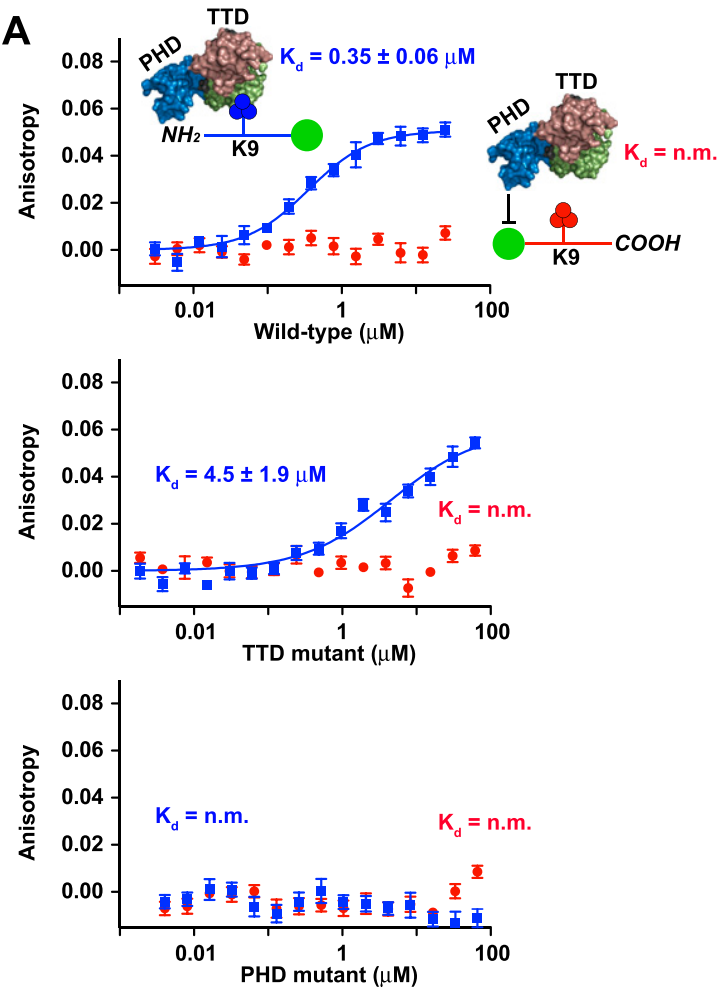

B

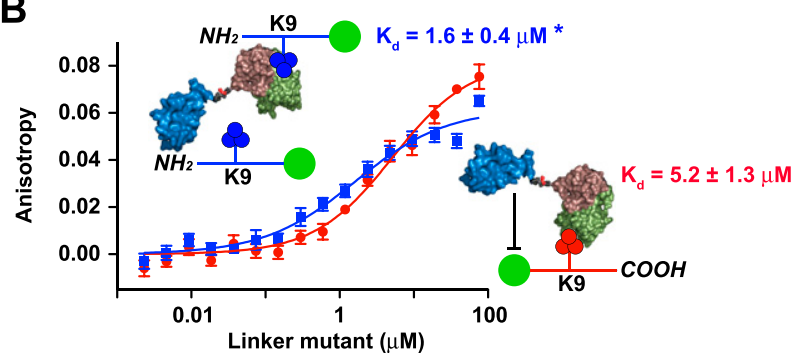

Figure 2. High-affinity interaction of UHRF1 with H3K9me3 peptides requires multivalent TTD and PHD engagement in cis. $(A, B)$ Fluorescence polarization binding assays of $\mathrm{H} 3_{1-20} \mathrm{~K} 9 \mathrm{me} 3$ peptides labeled with 5-carboxyfluorescein (5-FAM) at the $\mathrm{N}$ terminus (red) or $\mathrm{C}$ terminus (blue) with the indicated wild-type (WT) and mutant UHRF1 TTD-PHD proteins. Error bars represent $\mathrm{SD}$ for three independent experiments. All $\mathrm{K}_{\mathrm{d}}$ values were determined using a one-site binding model as described in the Materials and Methods. Asterisk in $B$ indicates that $\mathrm{K}_{\mathrm{d}}$ is likely an average contribution of two binding sites as suggested by published ITCbinding stoichiometry calculations (n-value) (Arita et al. 2012). (n.m) Not measurable; (TTD mutant) UHRF1 TTD-PHD Y188A; (PHD mutant) UHRF1 TTD-PHD D334A/E335A; (linker mutant) UHRF1 TTD-PHD R295A/R296A. Cartoons depict predicted peptidebinding modes for wild-type $(A$, top panel) and Linker mutant (B) UHRF1 TTD-PHD based on experimental observations.

$\mathrm{H} 3_{1-5}$ peptides containing either D-alanine or D-valine, demonstrating that stereochemistry at the first position is critical for PHD binding and that the functional PHD is likely able to accommodate more bulky side chains (Supplemental Fig. S1D).

Collectively, these results demonstrate that the highaffinity interaction of the UHRF1 TTD-PHD for H3K9me2 and $\mathrm{H} 3 \mathrm{~K} 9 \mathrm{me} 3$ peptides requires multivalent engagement of H3K9 methylation by the UHRF1 TTD and the H3 N terminus by the UHRF1 PHD. Furthermore, the UHRF1 TTD-PHD cannot maintain a measurable interaction with $\mathrm{H} 3 \mathrm{~K} 9 \mathrm{me} 2 / 3$ in the absence of a functional PHD that interacts with the $\mathrm{H} 3 \mathrm{~N}$ terminus, while TTD-PHD affinity for $\mathrm{H} 3 \mathrm{~K} 9 \mathrm{me} 2 / 3$ peptides is reduced $\sim 10$-fold in the absence of a functional methyllysine binding pocket within the TTD (Fig. 2A).

\section{The UHRF1 PHD-linker fragment physically} occludes alternative $H 3$ peptide-binding poses with the UHRF1 TTD

Strong experimental evidence shows that the UHRF1 TTD can function as a $\mathrm{H} 3 \mathrm{~K} 9 \mathrm{me} 2 / 3$ reader domain in isolation (Supplemental Fig. S1E; Nady et al. 2011; Arita et al. 2012; Rothbart et al. 2012a; Cheng et al. 2013), but our data demonstrate that in the context of the dual domain, the TTD has no measurable affinity for $\mathrm{H} 3 \mathrm{~K} 9 \mathrm{me} 2 / 3$ peptides in the absence of PHD function. This led us to question why the physical linkage of the TTD to the PHD finger renders this $\mathrm{H} 3 \mathrm{~K} 9$ reader domain incapable of engaging $\mathrm{H} 3 \mathrm{~K} 9$ methylated histone tails in the absence of PHD coordination of the $\mathrm{H} 3 \mathrm{~N}$ terminus. In the crystal structure of the UHRF1 TTD-PHD bound to H3K9me3 (Protein Data Bank [PDB]: 3ASK) (Arita et al. 2012), the 15-amino-acid region (linker) connecting the TTD and PHD domains (amino acids 286-300) resides in the same binding groove occupied by the $\mathrm{H} 3$ peptide in the solution structure of the isolated UHRF1 TTD (PDB: 2L3R) (Fig. 1B,C; Nady et al. 2011). Here, we refer to this H3-TTD interaction (PBD: 2L3R) (Nady et al. 2011) as an alternative H3-binding pose with respect to the TTD. Nuclear magnetic resonance (NMR) titration of the 15-residue TTD-PHD linker peptide confirms its interaction with the alternate $\mathrm{H} 3$ peptide-binding groove of the free TTD (Fig. 3F,G; Supplemental Fig. S4A), and ITC indicates that this intrinsic affinity of the free linker peptide for the TTD is weak $(>100 \mu \mathrm{M})$ in the absence of covalent interaction in the intact protein (Supplemental Fig. S4B).

Mutations of R295 and R296 or phosphorylation of S298, both of which disrupt the linker-TTD interaction, were previously suggested to uncouple the cooperative binding potential of the UHRF1 TTD from the PHD in the context of the dual domain (Arita et al. 2012). Consistent with these findings, a mutant of the linker region within the TTD-PHD (R295A/R296A) was able to bind $\mathrm{H}_{1-20} \mathrm{~K} 9 \mathrm{me} 3$ peptides fluorescently labeled at both the $\mathrm{N}$ and $\mathrm{C}$ termini (Fig. 2B). This supports a model in which dissociation of the linker from the TTD allows the alternate mode of $\mathrm{H} 3$ peptide binding with the TTD, an interaction that does not involve the $\mathrm{N}$ terminus of $\mathrm{H} 3$ and is therefore not affected by the $\mathrm{N}$-terminal fluorescent probe. This model also predicts that linker occupancy of the TTD peptide-binding groove would prevent the TTD from binding $\mathrm{H} 3 \mathrm{~K} 9 \mathrm{me} 2 / 3$ peptides in the alternative pose (Fig. 1B). To test this predicted occlusion function of the linker region, we compared the binding affinity of $\mathrm{N}$-terminally labeled $\mathrm{H} 3 \mathrm{~K} 9 \mathrm{me} 3$ peptides (which 
Rothbart et al.

A

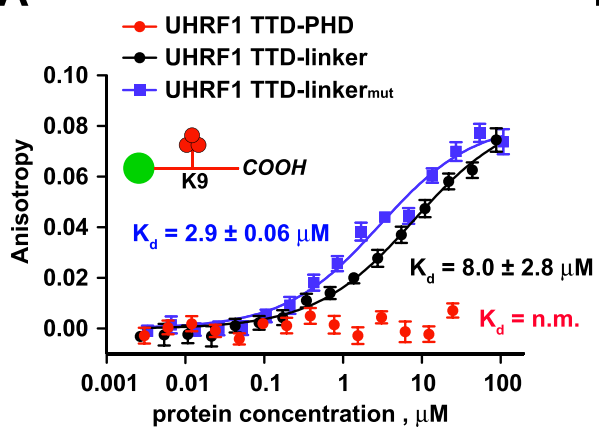

C

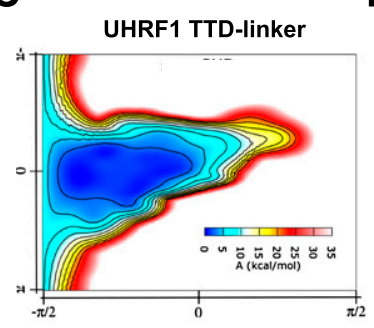

$F$

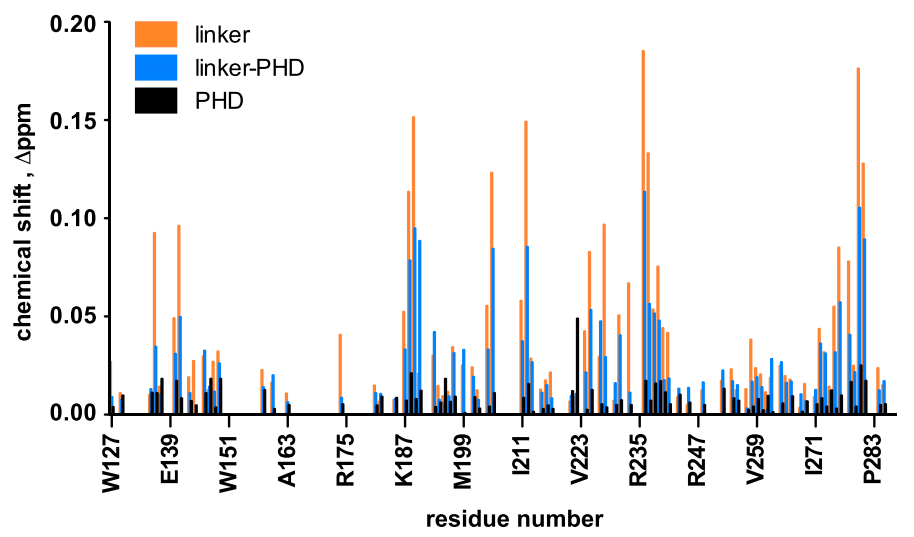

D

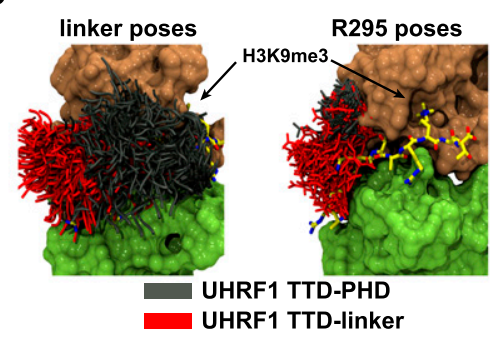

B

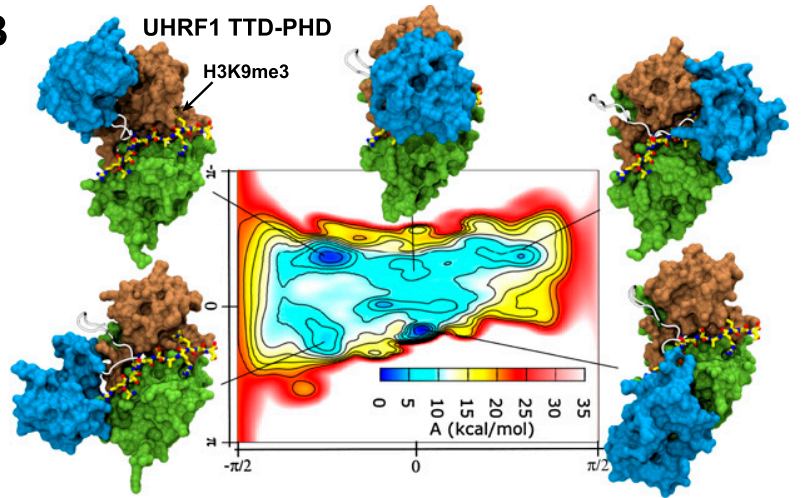

$\mathbf{E}$

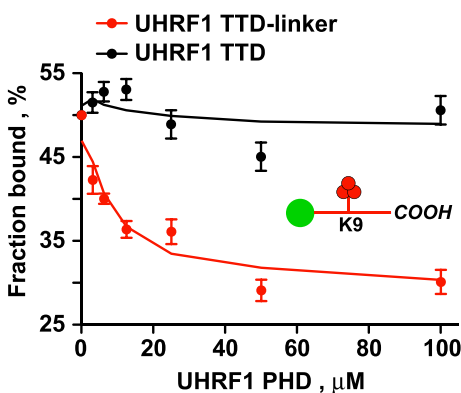

G

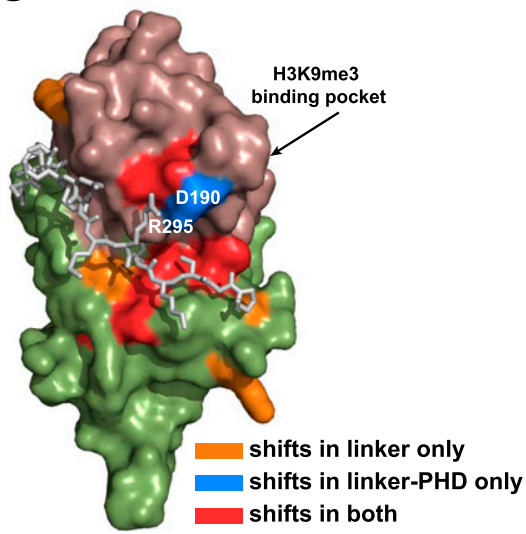

Figure 3. The UHRF1 linker-PHD physically occludes TTD coordination of H3K9 methylated peptides in alternative binding poses. $(A)$ Fluorescence polarization binding assays of N-terminal 5-FAM-H3 ${ }_{1-20} \mathrm{~K} 9 \mathrm{me} 3$ peptides with wild-type (WT; black) and linker mutant (blue) UHRF1 TTD-linker (amino acids 123-301) or wild-type UHRF1 TTD-PHD (red). Error bars represent SD for three independent experiments. $\mathrm{K}_{\mathrm{d}}$ values were determined using a one-site binding model as described in the Materials and Methods. (TTD-linker mut $_{\text {) UHRF1 TTD-linker }}$ R295A/R296A. (B) Estimate of the free-energy landscape in the TTD-PHD molecular dynamics simulation with several representative conformations. An $\mathrm{H}_{1-11} \mathrm{~K} 9$ me3 peptide (yellow) is modeled into the structure in the isolated TTD peptide-binding pose as a point of reference. The linker region (amino acids 286-301) is depicted as a white ribbon. Contours on the free energies are drawn every 4k $\beta T$, where $\mathrm{k} \beta$ is the Boltzmann constant and $\mathrm{T}$ is the temperature. $(C)$ Estimate of the free-energy landscape in the TTD-linker (amino acids 123-301) molecular dynamics simulation. Contours on the free energies are drawn every $4 \mathrm{k} \beta \mathrm{T}$, where $\mathrm{k} \beta$ is the Boltzmann constant and $\mathrm{T}$ is the temperature. (D) An overlay of linker (left) and R295 (right) conformations for the TTD-PHD (gray) and TTD-linker (red) molecular dynamics simulations. An $\mathrm{H}_{1-11} \mathrm{~K} 9 \mathrm{me} 3$ peptide (yellow) is modeled into the structure in the isolated TTD peptide-binding pose as a point of reference. (E) Fluorescence polarization competition of N-terminal 5-FAM-H3 ${ }_{1-20} \mathrm{~K} 9 \mathrm{me} 3$ peptides bound to UHRF1 TTD-linker (red) or UHRF1 TTD (black; amino acids 126-280) in the presence of the indicated concentrations of UHRF1 PHD (amino acids 301-366). Error bars represent SD for three independent experiments. $(F)$ Histogram profiles showing NMR chemical shift changes of the UHRF1 TTD (amino acids 126-285) upon addition of the linker (orange; amino acids 286-300), PHD (black; amino acids 310-366), or linker-PHD (blue; amino acids 286-387). (G) Surface representation of the UHRF1 TTD-linker (PDB: 3ASK). The linker region (amino acids 286-300) is depicted as white sticks. Significant NMR chemical shifts observed in titrations of the linker (orange), linker-PHD (blue), and both (red) are depicted.

can only bind the TTD in the alternative pose) with the TTD-PHD dual domain and with a protein fragment containing just the TTD and linker sequence (TTD-linker) and compared the latter with the disruptive R295A/R296A mutation in the linker region (TTD-linker ${ }_{\text {mut }}$ ) (Fig. 3A). Surprisingly, unlike the TTD-PHD dual domain, the TTD-linker was able to bind N-terminally tagged $\mathrm{H} 3 \mathrm{~K} 9 \mathrm{me} 3$, and this interaction was enhanced by the 
R295A/R296A linker mutation. Collectively, these results demonstrate that the linker region alone cannot fully occlude the alternative H3-binding mode of the TTD in the absence of the PHD, and they suggest that the linker functions with the PHD in some way to promote multivalent histone engagement by the dual TTD-PHD module.

To gain further insight into how the PHD and linker modulate the interaction of the TTD with the $\mathrm{H} 3$ tail, we first performed a series of microsecond-scale nonequilibrium molecular dynamics simulations for the UHRF1 TTD-PHD and UHRF1 TTD-linker (Fig. 3B-D; Supplemental Movie S1; Supplemental Fig. S3). Because we were interested in observing rare events (e.g., the dynamic rearrangement of the PHD or linker with respect to the TTD), we made use of an adaptive biasing potential (Dickson 2011) to accelerate conformational sampling and assess the free-energy landscapes. The TTD-PHD free-energy projection was designed to correlate directly with PHD positioning (see Materials and Methods for details), and the position of the PHD in the crystal structure (PDB: 3ASK) (Arita et al. 2012) is located at the origin of the free-energy map (Fig. 3B). The projected histograms from 10 400-nsec simulations of TTD-PHD are shown in Supplemental Figure S3C, and a collective average of the free-energy landscape is depicted in Figure 3B. Simulations of the TTD-PHD indicated a rugged freeenergy landscape created by nonspecific interactions between the PHD and the TTD-linker (Fig. 3B; Supplemental Fig. S3C). This simulation suggests that the PHD is "scanning" the TTD surface rather than residing in a single conformation relative to the TTD. The numerous nonspecific interactions of the PHD with the TTD result in a compact coordination of the linker and PHD near the TTD surface. Several metastable conformations of the PHD in this simulation are depicted in Figure 3B, including several poses that may physically occlude the TTD aromatic cage that coordinates methylated H3K9 (Nady et al. 2011). Notably, closer examination of the linker positions in the TTD-PHD simulations suggest that these weak interactions between TTD and PHD promote occupancy of the linker within the TTD peptidebinding groove, as depicted in Figure 3D.

In stark contrast, the TTD-linker simulation displays a much less complex free-energy landscape. The free-energy estimates from five independent simulations are shown in Supplemental Fig. S3D, and a collective average of the freeenergy landscape is depicted in Figure 3C. Here, the origin of the coordinates corresponds to the location of the $\mathrm{C}_{\alpha}$ atom of S301 in the crystal structure (PDB: 3ASK) (Arita et al. 2012). Consistently, in all five free-energy estimates, this reference position is rarely visited. Instead, the linker largely resides away from the TTD peptide-binding groove (Fig. 3D). Collectively, these simulations suggest a role for the PHD in maintaining the linker in or near the TTDbinding groove through transient interactions with the TTD. Hence, both the linker and PHD appear to block the TTD from binding $\mathrm{H} 3$ in the alternative binding pose.

Consistent with the model described above, the free UHRF1 PHD was able to perturb TTD-linker coordina- tion of H3K9me3 peptides fluorescently labeled at the $\mathrm{N}$ terminus (Fig. 3E). This observed competition seems to be specific to the UHRF1 PHD, as the BPTF PHD finger had no inhibitory effect on TTD-linker binding (Supplemental Fig. S2). However, the UHRF1 PHD was unable to perturb the isolated UHRF1 TTD from binding this peptide (Fig. 3E), demonstrating that the PHD inhibition seen in Figure 3E is mediated through interaction with the linker. Furthermore, analysis of the HSQC spectra of UHRF1 TTD titrated with linker peptide, PHD, and linker-PHD demonstrated that the majority of significant chemical shift changes observed are a result of interaction between the linker and the TTD (Fig. 3F; Supplemental Fig. S4). Both molecular dynamics and NMR titrations suggest that the PHD does not engage in specific interactions with the TTD (Fig. 3F; Supplemental Fig. S4). Additionally, discreet differences in chemical shift changes observed for the TTD in the linker and linker-PHD titrations suggest a role for the PHD in finetuning the orientation of the linker in the TTD groove. For example, several significant chemical shift changes for residues outside of the TTD groove (e.g., K136, N228, $\mathrm{K} 233$, and E278) in the linker titration were absent in the linker-PHD titration (Fig. 3F,G; Supplemental Fig. S4). Furthermore, D190, shown to play key roles in the interaction of the isolated TTD with the H3 tail (Nady et al. 2011) and the TTD-PHD with the linker (Arita et al. 2012), displayed a significant chemical shift change in the linker-PHD titration only (Fig. 3F,G; Supplemental Fig. S4). Collectively, these results suggest a key role for the PHD in preventing TTD binding to $\mathrm{H} 3$ peptides in the alternative pose and reveal the importance of the coordinated ensemble of TTD-linker-PHD conformations in UHRF1 multivalent histone engagement, in which the TTD-linker-PHD module reads the PTM status of the H3 tail from Ala 1 through Lys 9.

\section{UHRF1 TTD-PHD multivalent histone engagement in cis is required to facilitate DNA methylation maintenance}

We next sought to determine whether UHRF1 TTD-PHD multivalent histone engagement is important for the interaction of UHRF1 with bulk chromatin in cells. Wild-type and TTD (Y188A) and PHD (D334A/E335A) mutants of full-length UHRF1 were transiently expressed in HeLa cells for $72 \mathrm{~h}$, followed by biochemical separation into chromatin-enriched and soluble fractions (Fig. 4A). Consistent with our previous findings (Rothbart et al. 2012a), the TTD mutant was unable to bind bulk chromatin, and protein was found primarily in the soluble fraction (Fig. 4A,C). Strikingly, similar results were obtained with both the PHD mutant and linker mutations (R295A/ R296A) that uncouple H3 N-terminal binding or the histone-binding properties of TTD from the PHD, respectively (Fig. 4A,B). Consistently, confocal microscopy of TTD, PHD, and linker mutants of full-length GFPtagged UHRF1 in HEK293 cells showed that these mutants remain in the nucleus but no longer associate with DAPI-dense pericentric heterochromatin (Fig. 3C). 
A

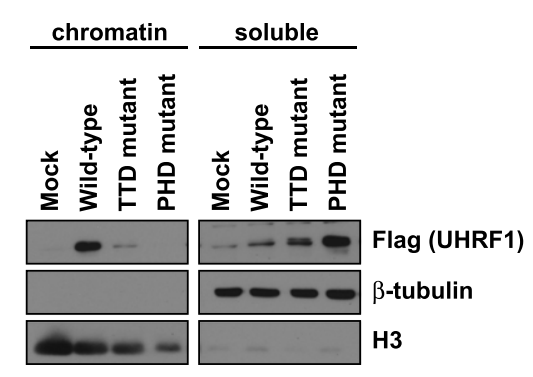

D

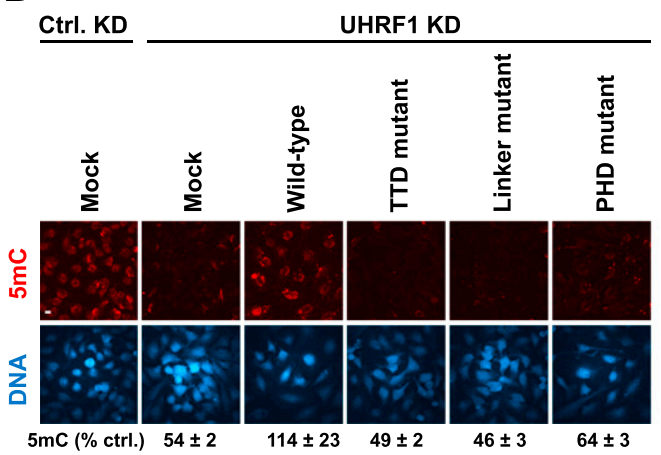

B

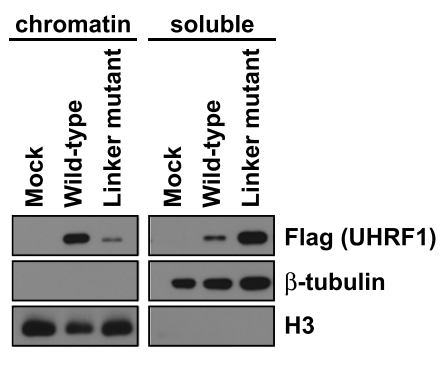

E

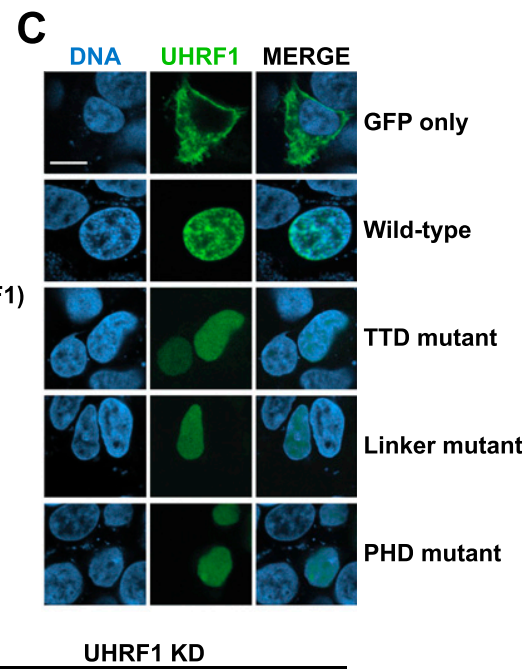

Figure 4. The UHRF1 TTD-PHD functions as a single unit in cells to maintain global DNA methylation. $(A, B)$ Western blot analysis of wild-type (WT) and the indicated mutant forms of full-length UHRF1 in HeLa cell lysates biochemically separated into chromatin and soluble fractions. ( $\beta$-Tubulin and H3) Fractionation controls; (Mock) no DNA transfection. (C) Representative confocal microscopy images of GFP-tagged wild-type and mutant forms of full-length UHRF1 in HEK293 cells. (GFP only) Transfection of empty GFP vector. Bars, $10 \mu \mathrm{m}$. (D) Representative immunofluorescence staining for $5 \mathrm{mC}$ in control and UHRF1 knockdown HeLa cells after genetic complementation with wild-type and mutant forms of full-length UHRF1. (Ctrl. KD) Nontargeted shRNA; (Mock) transfection in the absence of DNA. Bars, $10 \mu \mathrm{m}$. Error is represented as \pm SD. (E) Methylation-specific PCR for IGS-rDNA in control and UHRF1 knockdown HeLa cells after genetic complementation with wild-type and mutant forms of full-length UHRF1. Representative unmethylated (U) and methylated (M) gene-specific PCR products are shown. (Ctrl. KD) Nontargeted shRNA; (Mock) transfection in the absence of DNA. Error is represented as \pm SD.

We further hypothesized that the ability of UHRF1 to facilitate DNA methylation maintenance may require coordinated multivalent histone engagement. We showed previously that UHRF1 knockdown with shRNAs in HeLa cells resulted in $\sim 60 \%$ reduction in global $5 \mathrm{mC}$ content (as analyzed by immunofluorescence), and reintroduction of wild-type full-length UHRF1 (but not a TTD mutant [Y188A]) was able to restore DNA methylation in these cells (Fig. 4D; Rothbart et al. 2012a). Using this system, we queried whether PHD histone-binding mutants (D334A/E335A) or linker mutants (R295A/R296A) could genetically complement for UHRF1 knockdown. Consistent with the notion that UHRF1 DNA methylation maintenance function requires the physical association of UHRF1 with chromatin, neither UHRF1 PHD nor linker mutants were able to restore global DNA methylation levels in UHRF1 knockdown HeLa cells (Fig. 4D). To further examine the role of UHRF1 histone multivalency in DNA methylation maintenance, we examined the methylation status of a CpG island from the 5' end of the intergenic spacer of ribosomal DNA (IGS-rDNA) using methylation-specific PCR (Herman et al. 1996). We and others have shown that DNA methylation at this locus is regulated by UHRF1 (Bostick et al. 2007; Rothbart et al. 2012a). Consistent with our previous findings, knockdown of UHRF1 in HeLa cells diminished DNA methylation at this locus, and transient expression of wild-type (but not TTD mutant) UHRF1 partially restored DNA methylation (Fig. 4E). Furthermore, neither linker nor PHD mutants of UHRF1 were able to restore DNA methylation at this locus (Fig. 4E). Collectively, these results provide definitive evidence that linked histonebinding domains of an effector protein must act coordinately in cis to functionally engage chromatin in cells and that this binding is critically important to mediate a fundamental downstream epigenetic event in chromatin-DNA methylation maintenance.

\section{Discussion}

Our studies comprehensively define the contributions of the linked TTD and PHD domains of UHRF1 to multivalent histone engagement. This dynamic ensemble is likely sampling multiple conformations within the chromatin microenvironment until an appropriately marked H3 tail is engaged. Notably, the SRA domain of UHRF1 
harbors an additional chromatin-binding domain capable of recognizing hemimethylated DNA (i.e., DNA in need of maintenance methylation). As such, UHRF1 is one of a few proteins known to recognize both histone and DNA regulatory marks on chromatin. Unpublished findings from our laboratory and recent work by Liu et al. (2013) suggest an important role for SRA binding in cells, and careful examination of this apparent multivalent interaction with histones and DNA will be an important area of future biochemical study.

The original posit of the "histone code" hypothesis stated that there is a combinatorial code embedded in histone tails that is read by effector proteins to mediate a downstream biological event in chromatin (Strahl and Allis 2000). Much research over the past decade has provided support for this hypothesis, primarily through the cataloging of individual reader domains recognizing individual histone marks. Our results demonstrate that histone-binding proteins themselves have evolved to interpret complex chromatin signatures through linked and "collaborative" reader modules. Furthermore, the lowaffinity, but functionally independent, nature of the UHRF1 TTD, linker, and PHD domains suggests that multivalent chromatin-binding modules may be more susceptible to functional modulation by cellular events/factors such as PTMs (compared with a single high-affinity interaction).

Beyond UHRF1, these studies underscore the complexity of chromatin recognition likely to be harbored in effector proteins with closely spaced reader modules and within multiprotein complexes with multiple reader modules. While it remains important to define the specificity of reader domains in isolation, multivalent chromatin engagement by linked or coordinated reader domains is likely to be a more physiologically relevant mode of interpreting the complex language of chromatin modifications.

\section{Materials and methods}

\section{Materials}

Histone peptides were synthesized, purified, and analyzed as described (Rothbart et al. 2012b). Linker peptide (amino acids 286-300) used for NMR titrations was purchased from Genscript. Antibodies used in this study were as follows: anti-Flag (1:5000; Sigma, F1804), anti- $\beta$-tubulin (1:1000; Cell Signaling, 2146), anti-H3 (1:20,000; EpiCypher, 13-0001), and anti-5mC (1:100; Diagenode, Mab-081). Human cDNAs encoding the UHRF1 TTD-PHD and TTD-linker were cloned into pGEX-4T-1 (GE Lifesciences) as $\mathrm{N}$-terminal GST fusions for peptide microarray and fluorescence polarization studies, expressed in Escherichia coli BL21(DE3) using standard procedures, and purified with GST-Bind Resin (Novagen) according to the manufacturer's protocol. The human UHRF1 PHD for fluorescence polarization was a gift from Y. Shi (Harvard University). This $\mathrm{N}$-terminal 6x-His fusion was expressed in E. coli BL21(DE3) using standard procedures and was purified with Talon Resin (Clontech) according to the manufacturer's protocol. An N-terminal GST fusion of the BPTF PHD was a gift from A. Ruthenburg (University of Chicago) and was expressed and purified as described above. Full-length human UHRF1 was cloned into pCMV-Tag 2 (Agilent) as an N-terminal Flag fusion and into pEGCP-C1 (gift from M. Bedford, MD Anderson Cancer Center) as an $\mathrm{N}$-terminal GFP fusion for mammalian expression.
Point mutations were generated by QuickChange site-directed mutagenesis (Stratagene).

Histone peptide microarrays

Peptide synthesis and validation, microarray fabrication, effector protein hybridization and detection, and data analysis were performed essentially as described (Rothbart et al. 2012b) with the following modification. Each peptide listed in Supplemental Table S1 was spotted in triplicate eight times per array. Triplicate spots were averaged and treated as a single value for subsequent statistical analysis.

\section{Fluorescence polarization binding assays}

Peptides for fluorescence polarization were synthesized essentially as described (Rothbart et al. 2012b) with an additional 6-h coupling with three equivalents of 5-carboxyfluorescein (5-FAM) and diidopropylcarbodiimide and nine equivalents of diisopropylethylamine in 1:1 volume equivalents of DMF/DMSO. C-terminally modified peptides were synthesized with additional orthogonally protected lysine at the $\mathrm{C}$ terminus after selective deprotection of the $\varepsilon$-amino group that lysine 5-FAM was coupled to. Binding assays were performed in $50 \mu \mathrm{L}$ in black flat-bottom 384-well plates (Costar) as described (Rothbart et al. 2012a).

\section{Molecular dynamics}

Adaptive biasing potential (Dickson 2011) was implemented in GROMACS 4.5.5 (Hess et al. 2008). For the UHRF1 TTD-PHD, the collective variables were defined as the three Cartesian coordinates of the center of geometry of the PHD. The position of the PHD in the crystal structure (PDB: 3ASK) (Arita et al. 2012) is located at the origin of the free-energy map (Fig. 3B). For the TTD-linker, the collective variables were defined as the three Cartesian coordinates of the $\mathrm{C}_{\alpha}$ atom of residue Ser 301, the last residue of the linker. The position of the Ser $301 \mathrm{C}_{\alpha}$ in the TTD-PHD crystal structure is located at the origin of the coordinates in Figure 3C. A grid in collective variable space is shown for the UHRF1 TTD-PHD in Supplemental Figure S3A. For better visibility, the visitation histograms were projected onto a two-dimensional surface, as illustrated in Supplemental Figure S3B. During the simulations, the UHRF1 TTD backbone (up to residue Glu 285) was loosely restrained by a harmonic potential to eliminate rotations and translations of the TTD, allowing the motion of the PHD or linker to be tracked directly as movement in the collective variable grid. To further facilitate visualization and enable the comparison of free-energy landscapes, the crystal structure (PDB: 3ASK) (Arita et al. 2012) was taken as a reference. The TTD backbones of all simulation snapshots were aligned to the TTD backbone of the presimulation structure using visual molecular dynamics (Humphrey et al. 1996) before simulation. The motion of the PHD or linker in the simulations can thus be directly compared with the reference structure.

The Cartesian coordinate system used here was selected so that the origin was at the center of geometry of the TTD and the $Z$-axis pointed from the origin to the center of geometry of the PHD in the 3ASK structure (or in the case of the TTD-linker, to the $\mathrm{C}_{\alpha}$ atom of residue S301). The position of the $\mathrm{PHD}\left(\mathrm{C}_{\alpha}\right.$ atom of residue S301) was tracked as rotations around the $X$-axis and $Y$-axis of this coordinate system. The projected histograms were obtained by integrating over the radial component of the data at a fixed rotation around the $X$-axis and $Y$-axis. Rotations around the $X$-axis were denoted with $\theta_{1}$, and rotations around the $Y$-axis 
were denoted with $\theta_{2}$. The Euler-Rodrigues formula was used to express the rotations around an axis.

The bias parameters were $b=0.9, c=0.1 / \delta t=50 \mathrm{ps}^{-1}$, where $\delta t$ is the molecular dynamics time step. The Gaussian width was $\alpha=0.3 \mathrm{~nm}$. All simulations were fully solvated in TIP3P water at physiological salt conditions. For the UHRF1 TTD-PHD, the simulation box was a dodecahedron with a minimum distance of $17 \AA$ from the protein to the wall to allow for potential linker extension. This resulted in a total of 70,147 atoms after adding salt and water. For the TTD-linker, the box was a dodecahedron with a minimum distance of $1.3 \AA$ from the protein to the box wall, resulting in a total of 40,830 atoms after adding salt and water. The proteins were described by the OPLS-AA force field (Kaminski et al. 2001). For the TTD-PHD, bond and angle restraints were added to maintain the geometry of coordination with zinc as described (Peters et al. 2010). System construction included $5 \mathrm{nsec}$ of isothermal-isobaric equilibration at 1 bar. Production simulations were carried out in the canonical ensemble with stochastic velocity rescaling (Bussi et al. 2007). Van der Walls and direct electrostatic interactions used a 10 A cutoff. Long-range electrostatics were treated with the particle mesh Ewald approach with a grid spacing of $1.6 \AA$. The neighbor list was updated every five steps. Ten trajectories, each $400 \mathrm{nsec}$ in duration, were generated for the TTD-linker-PHD. Five trajectories, each 200 nsec long, were generated for the TTDlinker.

\section{NMR spectroscopy and data analysis}

The UHRF1 TTD (amino acids 126-285) and linker-PHD (amino acids 288-387) were cloned into pET28- MHL and pNICCH vectors, respectively. The UHRF1 PHD (amino acids 310-366) was cloned into a pET15b-MHL vector using the In-Fusion method (BD Biosciences). UHRF1 TTD was expressed and purified as previously described (Nady et al. 2011). UHRF1 linker-PHD and PHD were expressed in E. coli cultured in Terrific Broth medium following overnight induction at $15^{\circ} \mathrm{C}$ with $1 \mathrm{mM}$ IPTG, when OD600 reached 1.5. Cell pellets were resuspended in $20 \mathrm{mM}$ Tris- $\mathrm{HCl}(\mathrm{pH} 8.0), 0.5 \mathrm{M} \mathrm{NaCl}, 5 \%$ glycerol, $2 \mathrm{mM}$ Imidazole, $2 \mathrm{mM}$ BME, and $1 \mathrm{mM}$ PMSF. After sonication and centrifugation, Ni-NTA agarose beads were added to the clarified lysate, and binding to the beads was allowed to proceed for $1 \mathrm{~h}$. Bound protein was washed with $20 \mathrm{mM}$ Tris- $\mathrm{HCl}$ (pH 8.0), $0.5 \mathrm{M}$ $\mathrm{NaCl}, 5 \%$ glycerol, and $20 \mathrm{mM}$ Imidazole and eluted in similar buffer containing $250 \mathrm{mM}$ imidazole. The eluate was passed through a size exclusion S200 16/60 column and then dialyzed into $20 \mathrm{mM} \mathrm{NaPO} 4$ (pH 7.0), $0.25 \mathrm{M} \mathrm{NaCl}$, and $1 \mathrm{mM} \mathrm{DTT}$ at $4^{\circ} \mathrm{C}$. Chemical shift changes of residues on the UHRF1 TTD upon titration of unlabeled linker peptide (amino acids 286-300; Genscript), PHD, and linker-PHD, were mapped using prior available chemical shift assignments deposited in the Biological Magnetic Resonance Bank (BMRB) (Nady et al. 2011). ${ }^{1} \mathrm{H}-{ }^{15} \mathrm{~N}$ HSQC spectra were collected at $25^{\circ} \mathrm{C}$ with a Bruker Avance 500$\mathrm{MHz}$ spectrometer. Composite chemical shift changes $(\Delta \mathrm{ppm})$ were calculated using the equation $\left[\left(\Delta \mathrm{ppm}_{\mathrm{N}} / 6.5\right)^{2} \mathrm{~N}+\left(\Delta \mathrm{ppm}_{\mathrm{HN}}{ }^{2}\right)\right]^{0.5}$.

\section{ITC}

Proteins and peptides were extensively dialyzed into buffer containing $20 \mathrm{mM}$ Tris- $\mathrm{HCl}(\mathrm{pH} 8.0), 150 \mathrm{mM} \mathrm{NaCl}$, and $5 \%$ glycerol at $4^{\circ} \mathrm{C}$. ITC measurements were performed at $20^{\circ} \mathrm{C}$ with a MicroCal VP-ITC (GE Healthcare). Linker and H3K9me2 peptides at $500 \mathrm{uM}$ were titrated $(2510-\mu \mathrm{L}$ injections at 10-sec intervals) with $30 \mathrm{uM}$ UHRF1 TTD. Data points were fit to a one-site binding model using MicroCal Origin 7.0 software.

\section{Cell culture and manipulation}

HeLa and HEK293 (American Type Culture Collection) were cultured in MEM and DMEM (Gibco), respectively, supplemented with $10 \%$ FBS (PAA Laboratories), maintained in a $37^{\circ} \mathrm{C}$ incubator with $5 \% \mathrm{CO}_{2}$ and passaged every 2-3 d. Transient transfections were performed using TurboFect (Fermentas) according to the manufacturer's protocol. shRNA knockdown of UHRF1 in HeLa cells was described previously (Rothbart et al. 2012a). For GFP-UHRF1 analysis, transfected cultures of HEK293 cells growing in eight-well chamber slides (Lab-Tek) were fixed with $4 \%$ paraformaldehyde, washed with $1 \times$ PBS, and mounted using SlowFade Anti-fade (Life Technologies) containing DAPI. Images were acquired using an FV1000 multiphoton inverted confocal microscope (Olympus) at $64 \times$ magnification following excitation with 405-nm and 488-nm single-photon lasers.

\section{Chromatin fractionation}

Chromatin and associated proteins were isolated from asynchronously growing HeLa cells as described (Kuo et al. 2012; Rothbart et al. 2012a).

\section{DNA methylation analysis}

Cells were labeled with anti-5mC (Diagenode) essentially as described (Rothbart et al. 2012a). Images were acquired using an FV1000 multiphoton inverted confocal microscope (Olympus) at $60 \times$ magnification following excitation with $405-\mathrm{nm}$ and 633-nm single-photon lasers. Methylation percentage was derived from quantification of $5 \mathrm{mC}$ fluorescence normalized to DNA fluorescence from at least four optical fields. For methylation-specific PCR analysis, genomic DNA (gDNA) was isolated from transfected cells using a DNeasy blood and tissue kit (Qiagen) according to the manufacturer's protocol. Five-hundred nanograms of gDNA was bisulfite-converted and desulphonated using an EZ DNA Methylation-Gold kit (Zymo Research) according to the manufacturer's protocol. One microliter of bisulfite-converted gDNA was used to amplify IGS-rDNA using primers specific for methylated (sn primer, 5'-ACGAGAGTGA GAAGCGCGTGTTCGG-3'; asn primer, 5' ${ }^{\prime}$-TCGACCTCCCG AAATCGTACACCGAA- $3^{\prime}$ ) and unmethylated (sn primer, $5^{\prime}$-AT GAGAGTGAGAAGTGTGTGTTTGG-3'; asn primer, 5' -TCAA CCTCCCAAAATCATACACCAAA-3') sequences (Esteve et al. 2006). Thirty cycles of PCR were performed using EpiMark Polymerase (New England Biolabs) according to the manufacturer's protocol using annealing temperatures of $66.6^{\circ} \mathrm{C}$ (methylated primer pair) and $59^{\circ} \mathrm{C}$ (unmethylated primer pair) before resolving amplified DNA fragments by $12 \%$ native-PAGE.

\section{Acknowledgments}

We thank Shili Duan for cloning of constructs used for NMR titrations. This work was supported in part by grants from the National Institutes of Health (NIH) to B.D.S. (GM068088) and D.B.K. (GM090732 and GM100919); the Carolina Partnership and the University Cancer Research Fund, University of North Carolina at Chapel Hill to D.B.K.; and the Natural Sciences and Engineering Research Council of Canada to C.H.A. (372475-10). S.B.R. was supported by the University of North Carolina Lineberger Comprehensive Cancer Center Basic Sciences Training Program (T32CA09156) and a Post-doctoral Fellowship from the American Cancer Society (PF-13-085-01-DMC). The Structural Genomics Consortium is a registered charity (no. 1097737) that receives funds from AbbVie, Boehringer Ingelheim, the Canada Foundation for Innovation, the Canadian Institutes of Health 
Research, Genome Canada through the Ontario Genomics Institute (OGI-055), GlaxoSmithKline, Janssen, Lilly Canada, the Novartis Research Foundation, the Ontario Ministry of Economic Development and Innovation, Pfizer, Takeda, and the Wellcome Trust $(092809 / Z / 10 / Z)$. B.D.S. is a cofounder of EpiCypher, Inc. S.B.R. designed, performed, and analyzed peptide microarray, polarization, and cellular studies. B.M.D. designed, performed, and analyzed molecular dynamics simulations. M.S.O. and S.H. designed, performed, and analyzed NMR studies. M.S.O. also prepared protein for NMR and ITC and carried out and analyzed ITC studies. K.K. designed, synthesized, and analyzed peptides and contributed to the design of peptide microarray and polarization experiments. D.B.K. contributed to analysis of molecular dynamics. C.H.A. contributed to the design and analysis of NMR and ITC experiments. B.D.S. contributed to the analysis of peptide microarray, polarization, and cellular studies. All authors made key intellectual contributions. S.B.R, B.M.D., C.H.A., and B.D.S. wrote the manuscript.

\section{References}

Ali M, Yan K, Lalonde ME, Degerny C, Rothbart SB, Strahl BD, Cote J, Yang XJ, Kutateladze TG. 2012. Tandem PHD fingers of MORF/MOZ acetyltransferases display selectivity for acetylated histone $\mathrm{H} 3$ and are required for the association with chromatin. I Mol Biol 424: 328-338.

Arita K, Ariyoshi M, Tochio H, Nakamura Y, Shirakawa M. 2008. Recognition of hemi-methylated DNA by the SRA protein UHRF1 by a base-flipping mechanism. Nature 455: $818-821$.

Arita $\mathrm{K}$, Isogai $\mathrm{S}$, Oda $\mathrm{T}$, Unoki $\mathrm{M}$, Sugita $\mathrm{K}$, Sekiyama N, Kuwata K, Hamamoto R, Tochio H, Sato M, et al. 2012. Recognition of modification status on a histone $\mathrm{H} 3$ tail by linked histone reader modules of the epigenetic regulator UHRF1. Proc Natl Acad Sci 109: 12950-12955.

Avvakumov GV, Walker JR, Xue S, Li Y, Duan S, Bronner C, Arrowsmith CH, Dhe-Paganon S. 2008. Structural basis for recognition of hemi-methylated DNA by the SRA domain of human UHRF1. Nature 455: 822-825.

Bostick M, Kim JK, Esteve PO, Clark A, Pradhan S, Jacobsen SE. 2007. UHRF1 plays a role in maintaining DNA methylation in mammalian cells. Science 317: 1760-1764.

Bourc'his D, Xu GL, Lin CS, Bollman B, Bestor TH. 2001. Dnmt3L and the establishment of maternal genomic imprints. Science 294: 2536-2539.

Bussi G, Donadio D, Parrinello M. 2007. Canonical sampling through velocity rescaling. I Chem Phys 126: 014101.

Chen T, Hevi S, Gay F, Tsujimoto N, He T, Zhang B, Ueda Y, Li E. 2007. Complete inactivation of DNMT1 leads to mitotic catastrophe in human cancer cells. Nat Genet 39: 391-396.

Cheng J, Yang Y, Fang J, Xiao J, Zhu T, Chen F, Wang P, Li Z, Yang $\mathrm{H}, \mathrm{Xu}$ Y. 2013. Structural insight into coordinated recognition of trimethylated histone $\mathrm{H} 3$ lysine 9 (H3K9me3) by the plant homeodomain (PHD) and tandem tudor domain (TTD) of UHRF1 (ubiquitin-like, containing PHD and RING finger domains, 1) protein. J Biol Chem 288: 1329-1339.

Dickson BM. 2011. Approaching a parameter-free metadynamics. Phys Rev E Stat Nonlin Soft Matter Phys 84: 037701.

Ebert A, Lein S, Schotta G, Reuter G. 2006. Histone modification and the control of heterochromatic gene silencing in Drosophila. Chromosome Res 14: 377-392.

Ernst J, Kheradpour P, Mikkelsen TS, Shoresh N, Ward LD, Epstein CB, Zhang X, Wang L, Issner R, Coyne M, et al. 2011. Mapping and analysis of chromatin state dynamics in nine human cell types. Nature 473: 43-49.
Esteve PO, Chin HG, Smallwood A, Feehery GR, Gangisetty O, Karpf AR, Carey MF, Pradhan S. 2006. Direct interaction between DNMT1 and G9a coordinates DNA and histone methylation during replication. Genes Dev 20: 3089-3103.

Eustermann S, Yang JC, Law MJ, Amos R, Chapman LM, Jelinska C, Garrick D, Clynes D, Gibbons RJ, Rhodes D, et al. 2011. Combinatorial readout of histone H3 modifications specifies localization of ATRX to heterochromatin. Nat Struct Mol Biol 18: 777-782.

Frauer C, Hoffmann T, Bultmann S, Casa V, Cardoso MC, Antes I, Leonhardt H. 2011. Recognition of 5-hydroxymethylcytosine by the Uhrf1 SRA domain. PLOS ONE 6: e21306.

Fuchs SM, Krajewski K, Baker RW, Miller VL, Strahl BD. 2011. Influence of combinatorial histone modifications on antibody and effector protein recognition. Curr Biol 21: 53-58.

Grewal SI, Elgin SC. 2007. Transcription and RNA interference in the formation of heterochromatin. Nature 447: 399-406.

Hashimoto H, Horton JR, Zhang X, Bostick M, Jacobsen SE, Cheng X. 2008. The SRA domain of UHRF1 flips 5-methylcytosine out of the DNA helix. Nature 455: 826-829.

Hawkins RD, Hon GC, Lee LK, Ngo Q, Lister R, Pelizzola M, Edsall LE, Kuan S, Luu Y, Klugman S, et al. 2010. Distinct epigenomic landscapes of pluripotent and lineage-committed human cells. Cell Stem Cell 6: 479-491.

Herman JG, Graff JR, Myohanen S, Nelkin BD, Baylin SB. 1996. Methylation-specific PCR: A novel PCR assay for methylation status of CpG islands. Proc Natl Acad Sci 93: 98219826.

Hess B, Kutzner C, van der Spoel D, Lindahl E. 2008. GROMACS 4: Algorithms for highly efficient, load-balanced, and scalable molecular simulation. J Chem Theory Comput 4: 435-447.

Hu L, Li Z, Wang P, Lin Y, Xu Y. 2011. Crystal structure of PHD domain of UHRF1 and insights into recognition of unmodified histone H3 arginine residue 2. Cell Res 21: 1374-1378.

Humphrey W, Dalke A, Schulten K. 1996. VMD: Visual molecular dynamics. J Mol Graph 14: 33-38.

Jenuwein T, Allis CD. 2001. Translating the histone code. Science 293: 1074-1080.

Jia D, Jurkowska RZ, Zhang X, Jeltsch A, Cheng X. 2007. Structure of Dnmt3a bound to Dnmt3L suggests a model for de novo DNA methylation. Nature 449: 248-251.

Kaminski GA, Friesner RA, Tirado-Rives J, Jorgensen WL. 2001. Evaluation and reparametrization of the OPLS-AA force field for proteins via comparison with accurate quantum chemical calculations on peptides. J Phys Chem 105: 6474-6487.

Kouzarides T. 2007. Chromatin modifications and their function. Cell 128: 693-705.

Kuo AJ, Song J, Cheung P, Ishibe-Murakami S, Yamazoe S, Chen JK, Patel DJ, Gozani O. 2012. The BAH domain of ORC1 links H4K20me2 to DNA replication licensing and MeierGorlin syndrome. Nature 484: 115-119.

Liu X, Gao Q, Li P, Zhao Q, Zhang J, Li J, Koseki H, Wong J. 2013. UHRF1 targets DNMT1 for DNA methylation through cooperative binding of hemi-methylated DNA and methylated H3K9. Nat Commun 4: 1563.

Musselman CA, Lalonde ME, Cote J, Kutateladze TG. 2012a. Perceiving the epigenetic landscape through histone readers. Nat Struct Mol Biol 19: 1218-1227.

Musselman CA, Ramirez J, Sims JK, Mansfield RE, Oliver SS, Denu JM, Mackay JP, Wade PA, Hagman J, Kutateladze TG. 2012b. Bivalent recognition of nucleosomes by the tandem PHD fingers of the CHD4 ATPase is required for CHD4mediated repression. Proc Natl Acad Sci 109: 787-792.

Nady N, Lemak A, Walker JR, Avvakumov GV, Kareta MS, Achour M, Xue S, Duan S, Allali-Hassani A, Zuo X, et al. 
2011. Recognition of multivalent histone states associated with heterochromatin by UHRF1 protein. I Biol Chem 286: 24300-24311.

Okano M, Bell DW, Haber DA, Li E. 1999. DNA methyltransferases Dnmt3a and Dnmt3b are essential for de novo methylation and mammalian development. Cell 99: 247257.

Oliver SS, Musselman CA, Srinivasan R, Svaren JP, Kutateladze TG, Denu JM. 2012. Multivalent recognition of histone tails by the PHD fingers of CHD5. Biochemistry 51: 6534-6544.

Papait R, Pistore C, Negri D, Pecoraro D, Cantarini L, Bonapace IM. 2007. Np95 is implicated in pericentromeric heterochromatin replication and in major satellite silencing. Mol Biol Cell 18: 1098-1106.

Peters MB, Yang Y, Wang B, Fusti-Molnar L, Weaver MN, Merz KM. 2010. Structural survey of zinc-containing proteins and development of the zinc AMBER force field (ZAFF). I Chem Theory Comput 6: 2935-2947.

Qian C, Li S, Jakoncic J, Zeng L, Walsh MJ, Zhou MM. 2008. Structure and hemimethylated CpG binding of the SRA domain from human UHRF1. I Biol Chem 283: 34490-34494.

Qiu Y, Liu L, Zhao C, Han C, Li F, Zhang J, Wang Y, Li G, Mei Y, $\mathrm{Wu} \mathrm{M}$, et al. 2012. Combinatorial readout of unmodified H3R2 and acetylated H3K14 by the tandem PHD finger of MOZ reveals a regulatory mechanism for HOXA9 transcription. Genes Dev 26: 1376-1391.

Rajakumara E, Wang Z, Ma H, Hu L, Chen H, Lin Y, Guo R, Wu F, Li H, Lan F, et al. 2011. PHD finger recognition of unmodified histone H3R2 links UHRF1 to regulation of euchromatic gene expression. Mol Cell 43: 275-284.

Rothbart SB, Krajewski K, Nady N, Tempel W, Xue S, Badeaux AI, Barsyte-Lovejoy D, Martinez JY, Bedford MT, Fuchs SM, et al. 2012a. Association of UHRF1 with methylated H3K9 directs the maintenance of DNA methylation. Nat Struct Mol Biol 19: 1155-1160.

Rothbart SB, Krajewski K, Strahl BD, Fuchs SM. 2012b. Peptide microarrays to interrogate the 'histone code.' Methods Enzymol 512: 107-135.

Ruthenburg AJ, Li H, Patel DJ, Allis CD. 2007. Multivalent engagement of chromatin modifications by linked binding modules. Nat Rev Mol Cell Biol 8: 983-994.

Ruthenburg AJ, Li H, Milne TA, Dewell S, McGinty RK, Yuen M, Ueberheide B, Dou Y, Muir TW, Patel DJ, et al. 2011. Recognition of a mononucleosomal histone modification pattern by BPTF via multivalent interactions. Cell 145: 692-706

Sharif J, Muto M, Takebayashi S, Suetake I, Iwamatsu A, Endo TA, Shinga I, Mizutani-Koseki Y, Toyoda T, Okamura K, et al. 2007. The SRA protein Np95 mediates epigenetic inheritance by recruiting Dnmtl to methylated DNA. $\mathrm{Na}$ ture 450: 908-912.

Shogren-Knaak M, Ishii H, Sun JM, Pazin MJ, Davie JR, Peterson CL. 2006. Histone H4-K16 acetylation controls chromatin structure and protein interactions. Science 311: 844-847.

Spruijt CG, Gnerlich F, Smits AH, Pfaffeneder T, Jansen PW, Bauer C, Munzel M, Wagner M, Muller M, Khan F, et al. 2013. Dynamic readers for 5-(hydroxy)methylcytosine and its oxidized derivatives. Cell 152: 1146-1159.

Strahl BD, Allis CD. 2000. The language of covalent histone modifications. Nature 403: 41-45.

Tan M, Luo H, Lee S, Jin F, Yang JS, Montellier E, Buchou T, Cheng Z, Rousseaux S, Rajagopal N, et al. 2011. Identification of 67 histone marks and histone lysine crotonylation as a new type of histone modification. Cell 146: 1016-1028.

Taverna SD, Li H, Ruthenburg AJ, Allis CD, Patel DJ. 2007. How chromatin-binding modules interpret histone modifications:
Lessons from professional pocket pickers. Nat Struct Mol Biol 14: 1025-1040.

Tsai WW, Wang Z, Yiu TT, Akdemir KC, Xia W, Winter S, Tsai CY, Shi X, Schwarzer D, Plunkett W, et al. 2010. TRIM24 links a non-canonical histone signature to breast cancer. Nature 468: 927-932.

Wang C, Shen J, Yang Z, Chen P, Zhao B, Hu W, Lan W, Tong X, Wu H, Li G, et al. 2011. Structural basis for site-specific reading of unmodified $\mathrm{R} 2$ of histone $\mathrm{H} 3$ tail by UHRF1 PHD finger. Cell Res 21: 1379-1382.

Xi Q, Wang Z, Zaromytidou AI, Zhang XH, Chow-Tsang LF, Liu JX, Kim H, Barlas A, Manova-Todorova K, Kaartinen V, et al. 2011. A poised chromatin platform for TGF- $\beta$ access to master regulators. Cell 147: 1511-1524. 


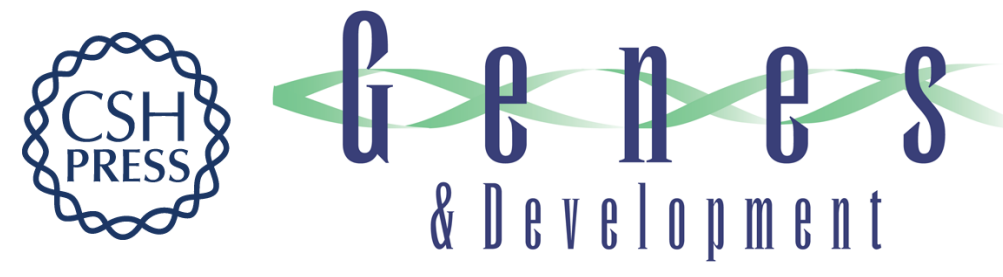

\section{Multivalent histone engagement by the linked tandem Tudor and PHD domains of UHRF1 is required for the epigenetic inheritance of DNA methylation}

Scott B. Rothbart, Bradley M. Dickson, Michelle S. Ong, et al.

Genes Dev. 2013, 27:

Access the most recent version at doi:10.1101/gad.220467.113

Supplemental http://genesdev.cshlp.org/content/suppl/2013/06/10/27.11.1288.DC1

Material

References This article cites 52 articles, 13 of which can be accessed free at:

http://genesdev.cshlp.org/content/27/11/1288.full.html\#ref-list-1

License

Email Alerting Receive free email alerts when new articles cite this article - sign up in the box at the top

Service right corner of the article or click here.

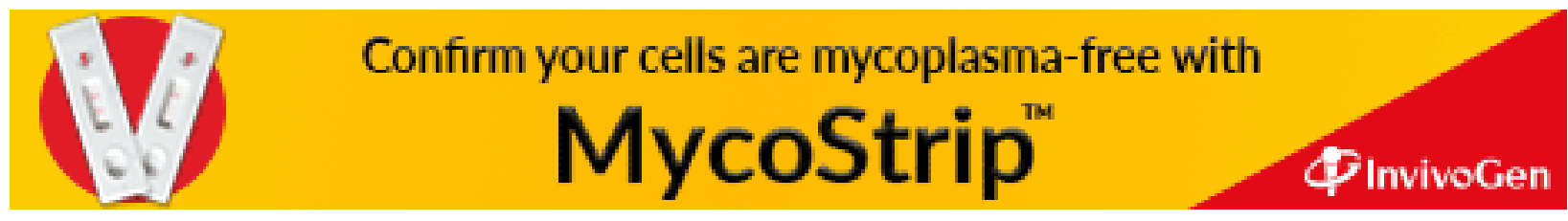

